\begin{tabular}{|c|c|}
\hline Title & $\begin{array}{l}\text { CRISPR Cas9-mediated in vivo gene editing reveals that neuronal } 5-\mathrm{HT} 1 \mathrm{~A} \text { receptors in the dorsal raphe nucleus } \\
\text { contribute to body temperature regulation in mice }\end{array}$ \\
\hline Author(s) & $\begin{array}{l}\text { Nishitani, Naoya; Ohmura, Y u; Nagay asu, Kazuki; Shibui, Norihiro; Kaneko, Shuji; Ohashi, A kiko; Y oshida, } \\
\text { Takay uki; Y amanaka, A kihiro; Y oshioka, Mitsuhiro }\end{array}$ \\
\hline Citation & $\begin{array}{l}\text { Brain research, 1719, } 243.252 \\
\text { https://doi.org/10.1016/.brainres.2019.06.009 }\end{array}$ \\
\hline Issue Date & 2019-09-15 \\
\hline Doc URL & http:/hdl .handle.net/2115/79239 \\
\hline Rights & $\begin{array}{l}\text { () 2019. This manuscript version is made available under the CC-BY-NC-ND } 4.0 \text { license } \\
\text { http://reativecommons.org/icenses/by-nc-nd/4.0/ }\end{array}$ \\
\hline Rights(URL) & http://creativecommons.org/icenses/by-nc-nd/4.0/ \\
\hline Type & article (author version) \\
\hline Additional Information & There are other files related to this item in HUSCAP. Check the above URL. \\
\hline File Information & Brain Res._1719_243.pdf \\
\hline
\end{tabular}

Instructions for use 
1 Title: CRISPR/Cas9-mediated in vivo gene editing reveals that neuronal $5-\mathrm{HT}_{1 \mathrm{~A}}$ receptors in the dorsal raphe nucleus contribute to body temperature regulation in mice

3 Article type: Research Article

4 Authors:

$5 \quad$ Naoya Nishitani ${ }^{1}$, Yu Ohmura ${ }^{1 *}$, Kazuki Nagayasu ${ }^{2}$, Norihiro Shibui ${ }^{2}$, Shuji Kaneko ${ }^{2}$, Akiko

6 Ohashi $^{3}$, Takayuki Yoshida ${ }^{1}$, Akihiro Yamanaka $^{4}$, Mitsuhiro Yoshioka ${ }^{1}$

7 Author Addresses: ${ }^{1}$ Department of Neuropharmacology, Faculty of Medicine and Graduate School of Medicine, Hokkaido University, N15 W7 Kita-ku, Sapporo 060-8638, Japan

2 Department of Molecular Pharmacology, Graduate School of Pharmaceutical Sciences, Kyoto University, Kyoto 606-8501, Japan

${ }^{3}$ Department of Anatomy, Nihon University School of Dentistry, Tokyo 101-8310, Japan

4 Department of Neuroscience II, Research Institute of Environmental Medicine (RIEM), Nagoya University, Nagoya 464-8601, Japan

\section{$16{ }^{*}$ Corresponding author:}

17 Yu Ohmura.

18 E-mail: gwd0701@yahoo.co.jp; yohmura@med.hokudai.ac.jp

19 TEL: +81-11-706-5059; FAX: +81-11-706-7872. 
ABSTRACT (250/250 words)

Serotonin (5-HT) in the central nervous system regulates a variety of biological functions, from the basic homeostatic control to higher brain functions, by acting on fourteen known receptor subtypes. However, it is still usually unclear which receptor subtype is responsible for a specific function due to the lack of highly selective ligands for most of these receptors. Although 5-HT receptor knockout mice are useful, the brain-wide distribution of various receptors makes it difficult to dissect receptor functions in specific and brain regions and cell types. Recent advances in CRISPR/Cas9-mediated in vivo genome editing technology may overcome this problem. In this study, we constructed a viral vector expressing a single guide (sg)RNA targeting Htr1a (sgHtr1a) and Cre recombinase under the control of a neuron-specific promoter. Injection of the viral vector into the dorsal raphe nucleus (DRN) of Cre-dependent Cas9 knock-in mice induced Cre-dependent Cas9 expression mainly in DRN serotonin and GABA neurons. Mismatch cleavage assay and Sanger sequencing showed insertion or deletion formation at the target site. 5-HT $1 \mathrm{~A}$ receptor agonist-induced hypothermia was attenuated and antidepressant effect of a selective serotonin reuptake inhibitor (SSRI) was enhanced by microinjection of the viral vector expressing sgHtr1a into the DRN of Cre-dependent Cas9 knock-in mice. These results suggest that this in vivo CRISPR/Cas9-mediated 5-HT receptor gene knockout strategy provides a reliable and low-cost method for elucidating 5-HT receptor functions in specific cell types and brain regions. Further, we demonstrate that the neuronal 5- $\mathrm{HT}_{1 \mathrm{~A}}$ receptor in the DRN regulates body temperature and antidepressant effect of SSRI.

KEYWORDS: genome editing; serotonergic; rectal temperature 
1

\section{Introduction}

The functions of central serotonergic systems remain elusive partly because of the diversity of serotonin receptors. Indeed, 14 subtypes of the serotonin (5-HT) receptor have been identified so far (Hannon and Hoyer, 2008; Hoyer et al., 1994), and in most cases, pharmacological methods have failed to manipulate each receptor exclusively partly because of amino acid sequence similarity among 5-HT receptor subtypes (Hannon and Hoyer, 2008; Hoyer et al., 1994). Gene knockout mice can overcome shortcomings of pharmacological techniques, but it is impractical to obtain and breed knockout mice for all subtypes in most laboratories. Moreover, it is still difficult to specify the brain regions and types of cells involved in the observed functional changes. Thus, we need an easier and more cost-effective strategy to knockout 5-HT receptor genes in specific brain regions and cell types.

Recent developments in CRISPR/Cas9-mediated gene editing techniques (Jinek et al., 2012) may provide a solution. A recent study demonstrated that a specific gene in a selected brain region can be knocked out by injecting viral vector expressing single guide (sg)RNA and Cre recombinase to that target specific brain regions of Cre-dependent Cas9 knock-in mice (Platt et al., 2014). Therefore, we speculated if it is feasible to knockout 5-HT receptor genes by injecting a viral vector expressing a targeted sgRNA into Cre-dependent Cas9 knock-in mice. This approach would provide easier and lower-cost knockout of 5-HT receptor genes in specific cell types and brain regions because only one type of transgenic mice (Cre-dependent Cas9 knock-in) is required to knockout any one of the 14 5-HT receptor subtypes.

In the present study, we chose the gene encoding the 5-HT $1 \mathrm{~A}$ receptor and targeted the dorsal raphe nucleus (DRN), an origin of serotonergic projections to the forebrain, because $5-\mathrm{HT}_{1 \mathrm{~A}}$ receptors are densely expressed in the DRN and their function, body temperature regulation and 
2 Heisler et al., 1998; Hillegaart, 1991; Richardson-Jones et al., 2010). Moreover, the 5-HT $1 \mathrm{~A}$

inhibition of serotonin neuron firing, are well established (Craven et al., 1994; Gartside et al., 1995; receptor is the most thoroughly studied of 5-HT receptors, so it is a particularly suitable target to test the utility of this gene knockout strategy.

First, we tested whether the $5-\mathrm{HT}_{1 \mathrm{~A}}$ receptor gene could be edited by designed guide RNAs in vitro. Second, we injected viral vectors expressing sgRNA and Cre recombinase into

Cre-dependent Cas9 knock-in mice, and examined whether Cas9 was expressed in virus-infected cells by immunohistochemistry, and whether the 5-HT $1 \mathrm{~A}$ receptor gene was edited by PCR amplification of genomic DNA. A resolvase detecting the mismatched heteroduplex DNA and a conventional sequencer were used to confirm the gene editing. Third, we determined the types of neurons infected by our viral vectors because some studies have demonstrated that some selectively infect specific cell types (Nathanson et al., 2009). Moreover, 5-HT1A receptors are expressed not only in serotonin neurons but also in GABA neurons of the DRN (Bonnavion et al., 2010). Finally, we tested whether 5- $\mathrm{HT}_{1 \mathrm{~A}}$ receptor agonist-induced hypothermia was reduced and antidepressant effect of selective serotonin reuptake inhibitor (SSRI) was enhanced in

Cre-dependent Cas9 knock-in mice microinjected with sgRNA expression viral vectors into the DRN. In addition, we examined whether 5- $\mathrm{HT}_{1 \mathrm{~A}}$ receptor agonist or $5-\mathrm{HT}_{1 \mathrm{~A}}$ receptor knockout in the DRN could affect 5-HT metabolism.

\section{RESULTS}

\subsection{In vitro screening of gRNAs for editing efficacy at the Htr1a gene locus}

First we assessed the efficacy of designed gRNAs for gene editing of the mouse Htr1a (mHtr1a) gene locus in vitro using an EGxxFP assay (Mashiko et al., 2013). In this assay, the efficacy of gRNAs is assessed by the strength of the reconstituted enhanced green fluorescent protein (EGFP) 
fluorescence without Cel-I nuclease digestion of the PCR-amplified target region (Mashiko et al.,

2 2013). The Htr1a gene locus was cloned into the pCAG-EGxxFP vector, and the resultant construct

3 (pCAG-mHtr1a-EGxxFP) was co-transfected with pX330 expressing SpCas9 and

4 AAV:ITR-U6-sgRNA-hSyn-Cre expressing gRNAs into HEK293T cells. Forty-eight hours after

5 co-transfection, EGFP-positive cells were abundantly observed (Fig. 1A-C), whereas few

6 EGFP-positive cells were observed when cells were transfected with gRNA only or

7 pCAG-mHtr1a-EGxxFP only (Fig. 1D-G). Although this in vitro screening showed that all three

8 gRNAs had comparable efficacy, we selected gRNA\#1 because it was most likely to influence

9 protein expression and function because it targets the most upstream region of the mHtr1a gene

10 locus.

11 2.2. In vivo expression of Cas9 and gene editing of the 5-HT $\mathrm{T}_{1 \mathrm{~A}}$ receptor

12 The viral vectors used in the present study conferred expression of green fluorescent protein

13 (GFP) and Cre recombinase in the infected cells, and transgenic mice used in the present study

14 expressed FLAG-tagged Cas9 in a Cre-dependent manner. Thus, we first verified that all

15 GFP-positive cells expressed FLAG and vice versa in the virus-injected region (DRN) of

16 Cre-dependent Cas9 knock-in mice (Fig. 2A). In addition, the viral infection was localized

17 predominantly in the DRN (Supplementary Fig. 1).

18 A resolvase detecting the mismatched heteroduplex DNA generated cleavage products only in

19 the virus-injected region (DRN) of Cre-dependent Cas9 knock-in mice (Fig. 2B). The sizes of the

20 cleavage products were close to those expected from the targeted cleavage site (370 bp and $270 \mathrm{bp}$ ).

21 The frequency of insertion and deletion mutation (Indel) formation was estimated to be $8.65 \% \pm$

$221.67 \%$. No cleavage products were observed when we used the amplicons of the top 4 candidate

23 sequences for off-target cleavage (Fig. 2C).

24 Furthermore, the results of DNA sequencing showed multiple chromatogram peaks in 
virus-injected Cre-dependent Cas9 knock-in mice than in virus-injected wild type (WT) littermates.

2 The multiple chromatogram peaks were observed only around the targeted cleavage site (Fig 2D;

3 Supplementary Fig. 2). Recently, the Tracking of Indels by Decomposition (TIDE) assay was

4 reported to detect indel formation at a frequency similar to next generation sequencing (Sentmanat

5 et al., 2018). TIDE analysis revealed that overall efficiency was $17.94 \% \pm 2.58 \%$ and that the

6 introduced indels led mainly to a frameshift mutation (Fig 2E).

$7 \quad$ 2.3. Characteristics of neurons infected by viral vector

8 Histological analysis revealed that $10.6 \% \pm 1.4 \%$ of GFP-positive cells were immunoreactive

9 for tryptophan hydroxylase 2 (TPH2), a specific marker for serotonin neurons, and $83.5 \% \pm 5.5 \%$

10 of GFP-positive cells were immunoreactive for GAD67, a marker for GABA neurons, in

11 virus-injected Cre-dependent Cas9 knock-in mice (Fig. 3). Similarly, in virus-injected WT

12 littermates, $14.0 \% \pm 6.0 \%$ and $80.6 \% \pm 0.5 \%$ of GFP-positive cells were immunoreactive for TPH2

13 and GAD67, respectively (Fig.3). In addition, 15.97\% $\pm 2.08 \%$ of TPH2-positive cells were

14 GFP-positive in Cre-dependent Cas9 knock-in mice and 20.63\% \pm 7.29\% of TPH2-positive cells

15 were GFP-positive in WT littermates. There were no significant differences in these

16 immunopositivity ratios between Cre-dependent Cas9 knock-in and WT mice (Table 1;

17 TPH2-positive cells in GFP-positive cells: $\chi^{2}=2.03, p=0.153$, GAD67-positive cells in

18 GFP-positive cells: $\chi^{2}=3.74, p=0.053$, GFP-positive cells in TPH2-positive cells: $\chi^{2}=2.65, p=$ 19 0.103).

2.4. Cas9-mediated 5-HT $1 \mathrm{~A}$ receptor knockout reversed 5-HT $\mathrm{T}_{1 \mathrm{~A}}$ receptor agonist-induced

21 hypothermia

22 Two-way ANOVA showed that i.p. injection of 8-OH-DPAT (0.5 mg/kg), a 5-HT $1 \mathrm{~A} / 7$ receptor 23 agonist, induced hypothermia (Fig. 4A; a main effect of time, $F$ 2.38, 26.22 $=46.97, p<0.001$, with

24 Greenhouse-Geisser correction). However. the reduction in body temperature was significantly 
smaller in Cre-dependent Cas9 knock-in mice that received microinjection of viral vectors expressing sgRNA into the DRN than in WT littermates receiving the same microinjections (Fig. 4; time $\times$ genotype interaction, $F_{2.38,26.22}=5.56, p=0.007$, with Greenhouse-Geisser correction) One-way ANOVA for each time point revealed that body temperature differed between Cas9 transgenic and WT controls at 10, 20, and 30 min after 8-OH-DPAT injection (Fig. 4A; $F_{1,11}=5.67$, 13.04, and 9.77, $p=0.036,0.004$, and 0.01, respectively), while there were no differences between genotypes at other time points (Fig. $4 \mathrm{~A} ; F_{1,11}<4.37, N S$ ).

Moreover, two-way ANOVA revealed that NLX-112, a selective 5-HT $1 \mathrm{~A}$ receptor agonist, also induced hypothermia (Fig. 4B; a main effect of time, $F_{1.49,22.32}=47.99, p<0.001$, with Greenhouse-Geisser correction). This hypothermic effect was significantly attenuated in Cas9 transgenic compared to WT controls at 10-60 min after NLX-112 injection (Fig. 4B; two-way ANOVA, time $\times$ genotype interaction, $F_{1.48,22.32}=9.58, p=0.002$, with Greenhouse-Geisser correction; one-way ANOVA for each time point, $F_{1,15}=10.56,5.942,6.119,8.146,9.392$, and 8.923, $p=0.005,0.028,0.026,0.012,0.008$, and 0.009, respectively).

2.5. Cas9-mediated 5-HT $T_{1 \mathrm{~A}}$ receptor knockout enhanced selective serotonin reuptake inhibitor-induced antidepressant effect in the forced swim test.

Immobility time in the forced swim test was significantly shorter in Cas9 transgenic than in WT controls after i.p. injection of fluoxetine (10 mg/kg), a SSRI (Fig. 4C; $\left.t_{16}=3.929, p=0.0012\right)$.

2.6. Cas9-mediated 5-HT $\mathrm{T}_{1 \mathrm{~A}}$ receptor knockout did not alter 5-HT metabolism.

NLX-112 administration significantly reduced 5-HIAA/5-HT ratio in the DRN (Fig. 5A, $t_{6}=$ 2.82, $p=0.03$ ) while it did not alter 5-HT and 5-HIAA levels in the DRN ( ts $_{6}<0.52, p s>0.22$ ). Although NLX-112 administration tended to increase 5-HT levels in the ventral hippocampus (VH, $\left.t_{6}=2.35, p=0.057\right)$, it did not alter 5-HIAA or 5-HIAA/5-HT ratio $\left(t_{6}<1.90, p s>0.10\right)$. In the other brain regions, NLX-112 administration did not affect 5-HT, 5-HIAA levels, or 5-HIAA/5-HT 
ratio ( $t \mathrm{~s}_{6}<1.55$, $\left.p \mathrm{~s}>0.17\right)$. NLX-112 administration tended to reduce 5-HIAA/5-HT ratio in urine

2 (Fig. 5B, $\left.t_{6}=1.97, p=0.096\right)$, but it did not affect 5-HT or 5-HIAA levels in urine $\left(t \mathrm{~s}_{6}<1.47, p s>\right.$

3 0.19). However, 5-HT, 5-HIAA levels, and 5-HIAA/5-HT ratio in the brain tissues and urine were

4 comparable between Cas9 transgenic and WT controls after NLX-112 administration (Figs. 5C and

$\left.5 \quad 5 \mathrm{D}, t s_{15}<1.36, p s>0.19\right)$.

6

\section{3. DISCUSSION}

8 We observed efficient in vivo editing of Htr1a in Cre-dependent Cas9 knock-in mice injected

9 with a targeted sgRNA expression vector as predicted by in vitro screening (Figs. 1 and 2),

10 indicating that this in vitro screening test could be useful for choosing the optimal guide RNA

11 sequence (Mashiko et al., 2013). Cas9 was expressed only in virus-infected cells (Fig. 2A),

12 minimizing the risk of constitutive Cas9 expression-induced damage to cells during development.

13 Although a previous study reported that constitutive Cas9 expression did not impair the

14 physiological functions of CA1 pyramidal neurons in the hippocampus (Platt et al., 2014), another

15 study found that constitutive overexpression of an exogenous protein such as GCaMP6 caused

16 aberrant cortical activity (Steinmetz et al., 2017). Using this strategy, we demonstrated that 5-HT $1 \mathrm{~A}$

17 receptors in the DRN contribute to the regulation of body temperature and antidepressant effect of

18 SSRI (Fig. 4), though it might not be 5-HT $1 \mathrm{~A}$ receptors expressed by serotonin neurons (Fig. 3).

19 The efficiency of editing was approximately $8 \%$ to $18 \%$ in the present study (Figs. 2B and 2E).

20 Considering that we used a neuron-specific promotor, this efficiency is relatively high because the

21 isolated DRN slices also contain glia and stromal cells as well as neurons. Given that the

22 glia/neuron ratio in rodents ranges from around 3 to 6 (Herculano-Houzel, 2014), it is possible that

23 the gene encoding the 5- $\mathrm{HT}_{1 \mathrm{~A}}$ receptor was edited in most infected neurons.

24 Unfortunately, we could not find any 5-HT $\mathrm{HT}_{1 \mathrm{~A}}$ receptor selective antibodies. However, our 
CRISPR/Cas9-mediated 5-HT $1 \mathrm{~A}$ receptor knockout strategy will advance the development of

2 selective antibodies in the future and overcome this kind of problems (Baker, 2015). Although it is

3 best to check the selectivity of antibodies by using gene knockout mice, knockout mice are not

4 always available for most researchers. Easier and cost-effective CRISPR/Cas9-mediated knockout

$5 \quad$ strategy will resolve it because this strategy will be available for most researchers and because we

6 can check the selectivity of antibodies by using a brain slice of Cas9-mediated knockout mice. That

7 is, if an antibody labels Cas9-negative cells but not Cas9-expressing cell, the antibody will be

8 selective for the targeted protein.

9 A previous pharmacological study reported that microinjection of 8-OH-DPAT into the DRN, 10 but not the median raphe nucleus, decreased body temperature (Hillegaart, 1991). However, it is

11 known that 8-OH-DPAT is a 5- $\mathrm{HT}_{7}$ receptor agonist as well as a 5- $\mathrm{HT}_{1 \mathrm{~A}}$ receptor agonist (Hedlund

12 et al., 2004; Wood et al., 2000), and 5- $\mathrm{HT}_{7}$ receptors are also involved in regulating body

13 temperature (Hedlund et al., 2003; Hedlund et al., 2004). Although genetic studies using 5-HT $1 \mathrm{~A}$

14 receptor knockout/knockdown mice have shown that the 5- $\mathrm{HT}_{1 \mathrm{~A}}$ receptor regulates body

15 temperature (Heisler et al., 1998; Richardson-Jones et al., 2010), the responsible brain regions have

16 not yet been determined. Therefore, our results filled the gap between pharmacological and genetic

17 findings by showing a specific contribution of DRN 5- $\mathrm{HT}_{1 \mathrm{~A}}$ receptors. More, we demonstrate a

18 direct effect of $5-\mathrm{HT}_{1 \mathrm{~A}}$ receptor-expression neurons. The $5-\mathrm{HT}_{1 \mathrm{~A}}$ receptor is expressed in glial

19 cells as well as neurons (Hirst et al., 1998; Miyazaki et al., 2013; Whitaker-Azmitia et al., 1990),

20 but previous pharmacological and genetic studies did not discriminate between neurons and glia. In

21 the present study, we expressed Cas9 only in neurons by utilizing the hSyn promotor, and

22 demonstrate that neuronal $5-\mathrm{HT}_{1 \mathrm{~A}}$ receptors in the $\mathrm{DRN}$ are responsible for regulating body 23 temperature.

24 It has been reported that the stimulation of 5- $\mathrm{HT}_{1 \mathrm{~A}}$ receptor by 5-HT inhibits serotonin neuron 
firing and the inhibitory effect of SSRIs via $5 \mathrm{HT}_{1 \mathrm{~A}}$ receptor offsets increase of 5-HT release in the

2 frotal cortex (Craven et al., 1994; Gartside et al., 1995). Due to the offsetting effect, SSRIs have

3 often failed to exert sufficient antidepressant effects especially when fluoxetine and C57BL/6 mice

4 were used (Lucki et al., 2001). Indeed, we also failed to find antidepressant effects of fluoxetine in

5 WT mice (C57BL/6N mice, Supplementary Fig. 3B). Moreover, it has been suggested that the

6 blockade of 5- $\mathrm{HT}_{1 \mathrm{~A}}$ receptor might accelerate antidepressant effects of SSRIs (Artigas et al., 2001)

$7 \quad$ while a previous sutdy showed that knockdown of 5-HT 1 a autoreceptor itself only slightly affected

8 immobility in the forced swim test (Richardson-Jones et al., 2010). Thus, the enhancement of

9 antidepressant effect in Cas9-mediated 5-HT $1 \mathrm{~A}$ receptor knockout mice (Fig. 4C) likely reflect the

10 absence of this inhibitory effect.

11 In addition, 5-HT $1 \mathrm{~A}$ receptor agonist reduced 5-HT turnover in the DRN (Fig. 5A), consistent

12 with the previous study showing that $5-\mathrm{HT}_{1 \mathrm{~A} / 7}$ receptor agonist reduced 5 -HT turnover in the

13 brainstem (Veenema et al., 2005). However, 5-HT, 5-HIAA levels, and 5-HIAA/5-HT ratio were

14 comparable in urine and several brain tissues between Cas9-mediated 5-HT 1A receptor knockout

15 mice and WT mice (Fig. 5C, D). Because only a part of serotonin neurons (approx. 16\%) were

16 GFP-positive in Cre-dependent Cas9 knock-in mice, the 5-HT $1 \mathrm{~A}$ receptor agonist-induced

17 reduction of 5-HT turnover might not be fully reversed by 5-HT $\mathrm{H}_{1 \mathrm{~A}}$ receptor knockout in the present

18 study.

19 Most neurons infected by viral vector were GABA neurons while only a minority were serotonin neurons (Fig. 3). Given that 5-HT $1 \mathrm{~A}$ receptors are expressed in both serotonin and GABA neurons

21 of the DRN (Bonnavion et al., 2010), GABA neurons in the DRN may play a dominant role in body

22 temperature regulation. However, stimulation of 5- $\mathrm{HT}_{1 \mathrm{~A}}$ autoreceptors may also induce

23 hypothermia by decreasing serotonin release in the hypothalamus (Lin et al., 1998). This

24 uncertainty over the precise mechanisms could be addressed by taking advantage of Cre-dependent 
Cas9 expression; for example, SERT-Cre or GAD-Cre mice might be useful (Taniguchi et al., 2011;

2 Zhuang et al., 2005).

3 We cannot completely exclude the possibility that expression of GFP impaired cell functions,

4 thereby counteracting the effects of the 5-HT $1 \mathrm{~A}$ receptor agonist in Cre-dependent Cas9 knock-in

5 mice. However, our preliminary results using a viral vector lacking the guide RNA sequence

6 showed that the expression of GFP alone did not mitigate the effects of the 5-HT 1 A receptor agonist

7 (Supplementary Fig. 3). Thus, it is unlikely that GFP expression interfered with the hypothermic

8 effects of the $5-\mathrm{HT}_{1 \mathrm{~A}}$ receptor agonist.

9 We found GFP-positive cells in the adjacent brain areas to the DRN such as the periaqueductal 10 gray (Supplementary Fig. 1). However, the previous study showed that 5-HT1A receptor is 11 localized in the raphe nucleus in the midbrain (Chalmers and Watson, 1991). We confirmed that 12 any GFP-positive cells were not observed in other serotonergic raphe nuclei such as the median 13 raphe nucleus. Therefore, the physiological changes observed are most likely due to 5-HT $\mathrm{H}_{1 \mathrm{~A}}$ 14 receptor knockout in the DRN.

15 Although this strategy is promising, there is uncertainty about the off-target effects of 16 CRISPR/Cas9 (Zhang et al., 2015). We reduced the risk of off-target effects by utilizing recently 17 suggested algorithms (Naito et al., 2015) and checked some potential off-target sites (Fig. 2), but 18 we cannot completely exclude the possibility of off-target effects. However, the risk of off-target 19 effects is not as problematic compared to other methods such as pharmacological agents or RNAi 20 knockdown for preclinical studies (Boettcher and McManus, 2015). For clinical applications, more 21 precise tools are being developed (Chen et al., 2017; Shen et al., 2018). It might be prudent for the 22 time being to interpret the results obtained by CRISPR/Cas9 together with pharmacological results 23 or to combine CRISPR/Cas9 with pharmacological agents as in the present study.

24 Taken together, we successfully achieved in vivo genetic manipulation of the 5-HT 1 A receptor in 
1 a specific brain area and cell type, and revealed that neuronal $5-\mathrm{HT}_{1 \mathrm{~A}}$ receptors in the DRN can

2 induce hypothermia. If this approach becomes possible for all 5-HT receptor subtypes,

3 double/triple knockout and/or conditional knockout in specific brain regions and cell types will be

4 feasible at reasonable cost. Such an approach may be necessary for clinical studies. For instance, it

5 is unlikely that a single gene is responsible for any major psychiatric disorders (Arnedo et al., 2015).

6 Further, the physiological roles of specific 5-HT receptor subtypes depend on the expressing cells

7 as shown for other neurotransmitters (de Almeida and Mengod, 2008; Rey et al., 2012). This

8 realization will surely accelerate progress on elucidation of the distinct roles of 5-HT receptor

9 subtypes in psychiatric disorders. While only the first step, the present study could facilitate such

10 research by providing a tool for in vivo knockout of the $5-\mathrm{HT}_{1 \mathrm{~A}}$ receptor gene.

\section{4. Experimental procedures}

13 4.1. Design of guide RNAs and prediction of off-target sites.

14 Three guide RNA candidates for the $5-\mathrm{HT}_{1 \mathrm{~A}}$ receptor gene $(\mathrm{Htr} 1 a)$ were selected using

15 CRISPRdirect (Naito et al., 2015). We checked "show highly specific target only" on the website

16 (https://crispr.dbcls.jp/), and chose three sequences from the 18 candidates expected to produce

17 cleavage in the middle of the coding region:

18 Guide Candidate 1, GGGACAGGCGGCAACGATAC (TGG)

19 Guide Candidate 2, TGTGCGCCATCGCGCTAGAC (AGG)

20 Guide Candidate 3, (CCA)TCGCGCTAGACAGGTACTGG

21 Protospacer adjacent motif sites are in parentheses.

22 These three candidates were cloned into

23 AAV:ITR-U6-sgRNA(backbone)-hSyn-Cre-2A-EGFP-KASH-WPRE-shortPA-ITR

24 (AAV:ITR-U6-sgRNA-hSyn-Cre) via the SapI restriction enzyme site. The 
2 from Feng Zhang (Addgene plasmid \# 60231; http://n2t.net/addgene:60231; RRID:Addgene_60231).(Platt et al., 2014) the sequence used in the present in vivo study (Guide Candidate 1) to the web (http://cheetah.bioch.virginia.edu/AdliLab/CROP-IT/homepage.html). The top 4 off-target follows:

Off-Target Candidate 1. GaGAgAaGaGGCAACGATAgaGG Off-Target Candidate 2. aGaACAGGgtGCAACGATAgaGG Off-Target Candidate 3. cGGggtGGCtGCAACGATAtgGG Off-Target Candidate 4. caGgaAGGgGGCAACGATAggGG

Capital letters in these off-target candidates indicates matches with the target sequence and fewer than six mismatches were found by this tool.

\subsection{In vitro screening of $g R N A s$ by EGxxFP assay} 5'-GAGGCTAGCTGCAGGCAGGCATGGATATGTTCAG-3', mHtr1a target Rv: 5’-CTTGTCGACGCGGGATGGAGATGAGAAAGCCAAT-3'. The PCR-amplified DNA fragment was digested by NheI and SalI and then cloned into pCAG-EGxxFP (Mashiko et al., 2013) (Addgene \#50716) also digested by NheI and SalI using a DNA Ligation kit according to

AAV:ITR-U6-sgRNA(backbone)-hSyn-Cre-2A-EGFP-KASH-WPRE-shortPA-ITR was a gift

Candidates for off-target sites were selected using CROP-IT (Singh et al., 2015). We submitted candidates were tested by a resolvase assay as described in Section 4.5. The candidate sites were as lower-case letters indicate mismatches with the target sequence. No off-target candidate sites with

The Htr1A gene locus was PCR-amplified from mouse genomic DNA by Q5 DNA polymerase (New England Biolabs, Ipswich, MA, USA). Primer sequences were as follows: mHtr1a target Fw: manufacturer’s instructions (Takara Bio, Kusatsu, Japan). Vector pX330 (Cong et al., 2013) was obtained from Addgene (Watertown, MA, USA; Addgene \#42230). HEK293T cells were cultured 
in Dulbecco’s modified Eagles medium with 10\% fetal bovine serum and passaged using trypsin-EDTA. On the day of transfection, cells were trypsinized and seeded onto 24-well tissue culture plates (Greiner Bio-One, Kremsmünster, Austria) at $1 \times 10^{5}$ cells/well. Then, $267 \mathrm{ng}$ of AAV:ITR-U6-sgRNA-hSyn-Cre expressing gRNAs, 267 ng of pCAG-mHtr1A-EGxxFP, and 267

ng of pX330 were co-transfected using Lipofectamine 2000 (Thermo Fisher Scientific, Waltham, MA, USA). As negative controls, 267 ng of AAV:ITR-U6-sgRNA-hSyn-Cre expressing gRNAs and 534 ng of empty vector, or 267 ng of pCAG-mHtr1A-EGxxFP and 534 ng of empty vector were co-transfected using Lipofectamine 2000. Forty-eight hours after transfection, EGFP fluorescence was recorded under an inverted fluorescence microscope (TE200, Nikon, Tokyo, Japan) equipped with a digital camera (DS-L2, Nikon).

\subsection{Animals}

Adult male and female mice (C57BL/6N WTs or transgenic mice on the C57BL/6N background, aged $>56$ days at the start of the virus injection procedure) were used following the National Institutes of Health (NIH) policy (Clayton and Collins, 2014). Approximately 50\% of the animals were female, and we combined the data of male and female mice because there were no significant sex differences in the present study (data not shown). Cre-dependent Cas9 knock-in mice (Stock No: 024857, the Jackson Laboratory) were backcrossed to the C57BL/6N strain for more than four generations. The mice were housed in groups under an alternating light-dark cycle (light from 7 p.m. to 7 a.m.) at approximately $25^{\circ} \mathrm{C}$. All testing was performed during the dark period. The treatment of animals complied with the Guidelines for the Care and Use of Laboratory Animals of the Animal Research Committee of Hokkaido University. Two independent cohorts of mice were used, where cohort 1 underwent the body temperature measurement using 8-OH-DPAT, mismatch cleavage assay, Sanger sequencing and immunohistochemistry. Cohort 2 underwent the body temperature measurement using NLX-112, the forced swim test and the measurement of 
5-HT/5-HIAA tissue contents.

\subsection{Adeno-associated virus (AAV) production and purification}

All AAV vectors were produced using the AAV Helper-Free System (Agilent Technologies, Inc., Santa Clara, CA, USA) and purified as described previously (Inutsuka et al., 2016). Briefly, HEK293 cells were transfected with an AAV vector plasmid that included a gene of interest, pHelper, and pAAV-RC (serotype DJ; Cell Biolabs Inc, San Diego, CA, USA) using a standard calcium phosphate method. Three days later, transfected cells were collected and suspended in artificial cerebrospinal fluid (aCSF; $124 \mathrm{mM} \mathrm{NaCl}, 3 \mathrm{mM} \mathrm{KCl}, 26 \mathrm{mM} \mathrm{NaHCO}_{3}, 2 \mathrm{mM} \mathrm{CaCl}_{2}, 1$ $\mathrm{mM} \mathrm{MgSO}_{4}, 1.25 \mathrm{mM} \mathrm{KH}_{2} \mathrm{PO}_{4}$, and $10 \mathrm{mM}$ D-Glucose). Cell were disrupted by four freeze-thaw cycles, and the lysate was treated with benzonase nuclease (Merck, Darmstadt, Germany) at $45^{\circ} \mathrm{C}$ for $15 \mathrm{~min}$, followed by centrifugation two times at 16,000 $\mathrm{g}$ for $10 \mathrm{~min}$. The supernatant was used as the virus-containing solution. To measure the titer of purified virus, the supernatant was dissolved in artificial CSF and quantitative PCR was performed using the following primer pairs: woodchuck hepatitis virus posttranscriptional regulatory element (WPRE), WPRE-Forward: 5' -ACTGTGTTTGCTGACGCAAC-3', WPRE-Reverse: 5' -CAACACCACGGAATTGTCAG-3'; human growth hormone polyA-Forward: 5' -TGGGAAGACAACCTGTAGGG-3', human growth hormone polyA-Reverse: 5' -GTGAAACCCCGTCTCTACCA-3'.he AAV vector was stored at $-80^{\circ} \mathrm{C}$ in small aliquots until the day of experiment. The titer of AAV was estimated to be about 1 $\times 10^{13}$ copies $/ \mathrm{ml}$.

\subsection{Surgical and virus injection procedure}

Mice were anesthetized with isoflurane and fixed in a stereotaxic frame (Narishige, Tokyo, Japan). An injection cannula (35 gage; Nanofil, NF35BL-2; World Precision Instruments, Sarasota, FL, USA) was inserted into the DRN at coordinates $4.5 \mathrm{~mm}$ posterior to bregma, $1.5 \mathrm{~mm}$ lateral to 
1 the midline, $2.8 \mathrm{~mm}$ ventral to the dura, and at a $30^{\circ}$ angle from the vertical plane to avoid the

2 sagittal sinus. The virus solution $(0.3 \mu \mathrm{l})$ was infused over a period of $3 \mathrm{~min}$ at constant flow by a

3 microinjection pump (Ultra Micro Pump II and Micro4 controller, World Precision Instruments),

4 and the injector was left in place for 5 min after injection to allow diffusion. After surgery, the mice

$5 \quad$ were singly housed. Experiments (Sections 4.6-4.11) were conducted more than 5 weeks after

6 virus injection.

7 4.6. Immunohistochemistry

8 Immunohistochemistry and confocal microscopy were performed as described previously

9 (Shikanai et al., 2012). In brief, after intracardial perfusion with 4\% paraformaldehyde in PBS at

$10 \mathrm{pH}$ 7.2, brains were post-fixed overnight, placed in $0.1 \mathrm{M}$ PB containing $30 \%$ sucrose, and

11 sectioned at $50 \mu \mathrm{m}$. The primary antibodies used were mouse anti-GAD67 (1:5,000; MAB5406,

12 Chemicon, Temecula, CA, USA), rabbit anti-tryptophan hydroxylase $2(1: 10,000)$ (Nakamura et al.,

13 2008), and mouse anti-FLAG (1:1,000; F1804, Sigma Aldrich, St. Louis, MO, USA). The

14 secondary antibodies used were Alexa 647 (Invitrogen, Carlsbad, CA, USA) and

15 indodicarbocyanine (Cy5; Jackson ImmunoResearch, West Grove, PA, USA). Images were

16 captured with a confocal laser-scanning microscope (FV10i, Olympus, Tokyo, Japan). Quantitative

17 analyses were conducted on representative images from three mice per genotype.

18 4.7. Detection of CRISPR-Cas9-induced mutation using a resolvase

19 We prepared brain slices as described in Section 4.6., and further isolated the visual cortex and

20 DRN regions using surgical knives under a microscope. The isolated slices were placed in a tube

21 containing $100 \mu \mathrm{L}$ tissue lysate solution (20 mM Tris $\mathrm{HCl}$ [pH 8.0], 5 mM EDTA, $400 \mathrm{mM} \mathrm{NaCl}$,

$220.3 \% \mathrm{SDS}$, and $200 \mu \mathrm{g} / \mathrm{mL}$ proteinase K). These sample tubes were placed in a thermocycler (Verti

23 Thermal Cycler, Applied Biosystems, Waltham, MA, USA) and subjected to the following 
thermocycling parameters: $55^{\circ} \mathrm{C}$ for $30 \mathrm{~min}, 95^{\circ} \mathrm{C}$ for $10 \mathrm{~min}$, and cooling at $4{ }^{\circ} \mathrm{C}$. Then, PCR was conducted, followed by mutation detection using the Guide-it Mutation Detection Kit (Takara, Kyoto, Japan) according to manufacturer's protocol. In brief, PCR reactions were run using the following thermocycle: an initial denaturation step at $98^{\circ} \mathrm{C}$ for $2 \mathrm{~min}, 40$ cycles of $98^{\circ} \mathrm{C}$ for $10 \mathrm{~s}$, $70{ }^{\circ} \mathrm{C}$ for $15 \mathrm{~s}$, and $76^{\circ} \mathrm{C}$ for $1 \mathrm{~min}$, and then cooling at $4^{\circ} \mathrm{C}$. The primers are listed below: Target (Htr1a) primer (forward): CGCCGGTGAGTGCTCCTCTC Target (Htr1a) primer (reverse): CCGGGGCGTCCTCTTGTTCA Off-Target Candidate 1 primer (forward): TGCCTGTCAATACGTGCTGT Off-Target Candidate 1 primer (reverse): GAATGGGCCAACACACCAAC Off-Target Candidate 2 primer (forward): AACTCAGGTCTCCCAGTGGA Off-Target Candidate 2 primer (reverse): GAAAGGCCAGAGGACACAGG Off-Target Candidate 3 primer (forward): GCAGAGAGTTCATGCCTGGA Off-Target Candidate 3 primer (reverse): ACCAAACTGTAGACAAGCCGA Off-Target Candidate 4 primer (forward): CCACGGAGCTATGTGTCCAG Off-Target Candidate 4 primer (reverse): CTTCTTGTGGGTCCCGAACA

The PCR products were re-annealed to facilitate heteroduplex formation and then subjected to the following thermocycling parameters: $95^{\circ} \mathrm{C}$ for $5 \mathrm{~min}, 95^{\circ} \mathrm{C}$ to $85^{\circ} \mathrm{C}$ ramping at $2{ }^{\circ} \mathrm{C} / \mathrm{s}, 85^{\circ} \mathrm{C}$ to $25^{\circ} \mathrm{C}$ at $0.1{ }^{\circ} \mathrm{C} / \mathrm{s}$, and cooling at $4{ }^{\circ} \mathrm{C}$. Re-annealing products were treated with Guide-it Resolvase for $30 \mathrm{~min}$ at $37^{\circ} \mathrm{C}$ and electrophoresed on $2 \%$ agarose gels with a marker (100 bp DNA Ladder, Douourika, Sapporo, Japan). Intensity of each band was measured using ImageJ (http://imagej.nih.gov//ij/) and the percentage of insertion and deletion formation (\%Indel) was calculated using the formula \%Indel $=\left(1-\left[1-f_{\text {cut }}\right]^{0.5}\right) \times 100$ (Guschin et al., 2010), where $f_{\text {cut }}$ is the total density of cleaved bands divided by the sum of the density of uncleaved and cleaved bands. 4.8. DNA sequencing and TIDE analysis 
The PCR products were purified and sequenced by FASMAC Co., Ltd. (Kanagawa, Japan).

2 Sanger chromatograms were analyzed using the TIDE web tool (http://tide.nki.nl) (Brinkman et al., 3 2014).

4

5

6

\subsection{Drug Treatment}

(2R)-(+)-8-Hydroxy-2-(di-n-propylamino)tetralin hydrobromide (8-OH-DPAT) was purchased from Tocris Bioscience (Bristol, UK). NLX-112 was purchased from Sigma-Aldrich (St. Louis, USA). Fluoxetine was purchased from Tokyo Chemical Industry (Tokyo, Japan). 8-OH-DPAT and fluoxetine were dissolved in $0.9 \%$ saline. NLX-112 was dissolved in $0.9 \%$ saline with $1 \%$ DMSO. All drugs were dissolved to a concentration allowing injection at $10 \mathrm{ml} / \mathrm{kg}$.

\subsection{Body temperature measurement}

A microcomputer thermometer (MODEL 7001H; Physitemp, Clifton, NJ, USA) was used to assess body temperature. Mice were subjected to a sham handling procedure once a day for two consecutive days before the test. The procedure consisted of gently touching and restraining the animal for approximately 3 min. On the test day, the mice were gently hand-restrained and body temperature was measured intrarectally using a probe smeared with Vaseline (WAKO, Osaka, Japan). The probe was inserted to approximately $2 \mathrm{~cm}$ and kept in position for at least $5 \mathrm{~s}$ before recording. Body temperature was monitored every $10 \mathrm{~min}$. We started the drug injection procedure only after body temperature was stabilized $\left( \pm 0.2{ }^{\circ} \mathrm{C}\right.$ in three consecutive values) to avoid stress-induced changes. Three baseline values were recorded, and transgenic or WT littermate control mice received intraperitoneal (i.p.) injection of 8-OH-DPAT (0.5 mg/kg) or NLX-112 (0.5 $\mathrm{mg} / \mathrm{kg}$ ). After injection, body temperature was monitored over $60 \mathrm{~min}$.

\subsection{Forced swim test}

The forced swim test was performed as described previously (Tsutsui-Kimura et al., 2017). In brief, $30 \mathrm{~min}$ after intraperitoneal (i.p.) injection of fluoxetine (10 mg/kg), mice were placed in a 
cylinder glass (diameter, 23 cm; height, 30 cm; AGC techno glass, Shizuoka, Japan) containing

2

water at a temperature of $23{ }^{\circ} \mathrm{C} \pm 1{ }^{\circ} \mathrm{C}$ and a depth of $12 \mathrm{~cm}$. The test lasted $6 \mathrm{~min}$ and behaviors were video-recorded and scored later by an experimenter who was blind to the treatments. Only the last 4 min of behaviors were analyzed, and they were categorized as follows: floating, twitching/kicking, swimming, and climbing. The immobility was calculated as the sum of the durations of floating and twitching/kicking behaviors

\subsection{5-HT and 5-HIAA measurement}

Thirty minutes after the intraperitoneal injection of NLX-112 (0.5 mg/kg), mice were sacrificed by decapitation. The brain tissue including dorsal raphe (DRN), median raphe (MRN), dorsal striatum (DS) and ventral hippocampus (VH) were dissected on ice. Each sample was weighed, placed in a tube, immediately frozen in liquid nitrogen and kept frozen at $-80^{\circ}$ until analysis. For extraction of 5-HT and 5-HIAA, samples were added $200 \mu \mathrm{L}$ each of ice cold homogenization solution (0.9 M perchloric acid containing $1 \mathrm{mM}$ DTT and $0.05 \mu \mathrm{M}$ N-methylserotonin as an internal standard). The tissue block was dispersed by a 5 sec sonication and followed by another 5 sec for further homogenization. The homogenates were stored at $-80^{\circ}$ for determination of 5-HT, 5-HIAA (HPLC). Urine was taken at the time of decapitation and stock frozen at $-80^{\circ}$ until determination of 5-HT, 5-HIAA (HPLC) and creatinine (LabAssayTM Creatinine, FUJIFILM Wako 290-65901). Prior to HPLC analysis, the frozen homogenates were unfrozen on ice and spun to remove any precipitates. HPLC for determination of 5-HT and 5-HIAA was performed as described previously (Inoue et al., 1985) with slight modification. In brief, HPLC system was equipped with a fluorescence monitor (JASCO model, FP920) set at $290 \mathrm{~nm}$ and $350 \mathrm{~nm}$ for excitation and emission, respectively. The solid phase was ODS (4.6 × $250 \mathrm{~mm}$, JASCO, Finepak SIL-C18T5), and the mobile phase was a $100: 5: 7$ mixture of $40 \mathrm{mM}$ sodium acetate (adjusted to $\mathrm{pH} 3.5$ with formic acid), acetonitrile and methanol and the flow rate was $1 \mathrm{~mL} / \mathrm{min}$ ). 
13 mice.

\section{$15 \quad$ Funding}

16 This work was supported by JSPS KAKENHI grants (numbers: JP16K15552 and JP18K07545)

17 awarded to Y.O., JSPS KAKENHI grants (number: JP16K15125) awarded to K.N., JSPS

18 KAKENHI grants (number: JP16H05091) awarded to S.K., a CREST JST grant (number: JPMJCR1656) awarded to A.Y., and JSPS KAKENHI grants (number: JP16H05371) awarded to M.Y.

\section{ADDITIONAL INFORMATION}

23 Supplemental information accompanies this paper. 
2 Competing interests: The authors declare no competing interests.

3

4 
Arnedo, J., Svrakic, D.M., Del Val, C., Romero-Zaliz, R., Hernandez-Cuervo, H., Molecular Genetics of Schizophrenia, C., Fanous, A.H., Pato, M.T., Pato, C.N., de Erausquin, G.A., Cloninger, C.R., Zwir, I., 2015. Uncovering the hidden risk architecture of the schizophrenias: confirmation in three independent genome-wide association studies. Am J Psychiatry. 172, 139-53.

Artigas, F., Celada, P., Laruelle, M., Adell, A., 2001. How does pindolol improve antidepressant action? Trends Pharmacol Sci. 22, 224-8.

Boettcher, M., McManus, M.T., 2015. Choosing the Right Tool for the Job: RNAi, TALEN, or CRISPR. Mol Cell. 58, 575-85.

Bonnavion, P., Bernard, J.F., Hamon, M., Adrien, J., Fabre, V., 2010. Heterogeneous distribution of the serotonin $5-\mathrm{HT}(1 \mathrm{~A})$ receptor mRNA in chemically identified neurons of the mouse rostral brainstem: Implications for the role of serotonin in the regulation of wakefulness and REM sleep. J Comp Neurol. 518, 2744-70.

Brinkman, E.K., Chen, T., Amendola, M., van Steensel, B., 2014. Easy quantitative assessment of genome editing by sequence trace decomposition. Nucleic Acids Res. 42, e168.

Chalmers, D.T., Watson, S.J., 1991. Comparative anatomical distribution of 5-HT1A receptor mRNA and 5-HT1A binding in rat brain--a combined in situ hybridisation/in vitro receptor autoradiographic study. Brain Res. 561, 51-60.

Chen, J.S., Dagdas, Y.S., Kleinstiver, B.P., Welch, M.M., Sousa, A.A., Harrington, L.B., Sternberg, S.H., Joung, J.K., Yildiz, A., Doudna, J.A., 2017. Enhanced proofreading governs CRISPR-Cas9 targeting accuracy. Nature. 550, 407-410.

Clayton, J.A., Collins, F.S., 2014. Policy: NIH to balance sex in cell and animal studies. Nature. 509, 282-3.

Cong, L., Ran, F.A., Cox, D., Lin, S., Barretto, R., Habib, N., Hsu, P.D., Wu, X., Jiang, W., Marraffini, L.A., Zhang, F., 2013. Multiplex genome engineering using CRISPR/Cas systems. Science. 339, 819-23.

Craven, R., Grahame-Smith, D., Newberry, N., 1994. WAY-100635 and GR127935: effects on 5-hydroxytryptamine-containing neurones. Eur J Pharmacol. 271, R1-3.

de Almeida, J., Mengod, G., 2008. Serotonin 1A receptors in human and monkey prefrontal cortex are mainly expressed in pyramidal neurons and in a GABAergic interneuron subpopulation: implications for schizophrenia and its treatment. J Neurochem. 107, 488-96.

Gartside, S.E., Umbers, V., Hajos, M., Sharp, T., 1995. Interaction between a selective 5-HT1A receptor antagonist and an SSRI in vivo: effects on 5-HT cell firing and extracellular 5-HT. Br J Pharmacol. 115, 1064-70.

Guschin, D.Y., Waite, A.J., Katibah, G.E., Miller, J.C., Holmes, M.C., Rebar, E.J., 2010. A rapid and general assay for monitoring endogenous gene modification. Methods Mol Biol. 649, 247-56.

Hannon, J., Hoyer, D., 2008. Molecular biology of 5-HT receptors. Behav Brain Res. 195, 198-213.

Hedlund, P.B., Danielson, P.E., Thomas, E.A., Slanina, K., Carson, M.J., Sutcliffe, J.G., 2003. No hypothermic response to serotonin in 5-HT7 receptor knockout mice. Proc Natl Acad Sci U S A. 100, 1375-80.

Hedlund, P.B., Kelly, L., Mazur, C., Lovenberg, T., Sutcliffe, J.G., Bonaventure, P., 2004. 8-OH-DPAT acts on both 5-HT1A and 5-HT7 receptors to induce hypothermia in rodents. Eur J Pharmacol. 487, 125-32.

Heisler, L.K., Chu, H.M., Brennan, T.J., Danao, J.A., Bajwa, P., Parsons, L.H., Tecott, L.H., 1998. Elevated anxiety and antidepressant-like responses in serotonin 5-HT1A receptor mutant mice. Proc Natl Acad Sci U S A. 95, 15049-54.

Herculano-Houzel, S., 2014. The glia/neuron ratio: how it varies uniformly across brain structures and species and what that means for brain physiology and evolution. Glia. 62, 1377-91.

Hillegaart, V., 1991. Effects of local application of 5-HT and 8-OH-DPAT into the dorsal and median raphe nuclei on core temperature in the rat. Psychopharmacology (Berl). 103, 291-6.

Hirst, W.D., Cheung, N.Y., Rattray, M., Price, G.W., Wilkin, G.P., 1998. Cultured astrocytes express 
messenger RNA for multiple serotonin receptor subtypes, without functional coupling of 5-HT1 receptor subtypes to adenylyl cyclase. Brain Res Mol Brain Res. 61, 90-9.

Hoyer, D., Clarke, D.E., Fozard, J.R., Hartig, P.R., Martin, G.R., Mylecharane, E.J., Saxena, P.R., Humphrey, P.P., 1994. International Union of Pharmacology classification of receptors for 5-hydroxytryptamine (Serotonin). Pharmacol Rev. 46, 157-203.

Inoue, F., Hasegawa, H., Nishimura, M., Yanagisawa, M., Ichiyama, A., 1985. Distribution of 5 -hydroxytryptamine $(5 \mathrm{HT})$ in tissue of a mutant mouse deficient in mast cell (W/Wv). Demonstration of the contribution of mast cells to the $5 \mathrm{HT}$ content in various organs. Agents Actions. 16, 295-301.

Inutsuka, A., Yamashita, A., Chowdhury, S., Nakai, J., Ohkura, M., Taguchi, T., Yamanaka, A., 2016. The integrative role of orexin/hypocretin neurons in nociceptive perception and analgesic regulation. Sci Rep. 6, 29480.

Jinek, M., Chylinski, K., Fonfara, I., Hauer, M., Doudna, J.A., Charpentier, E., 2012. A programmable dual-RNA-guided DNA endonuclease in adaptive bacterial immunity. Science. 337, 816-21.

Lin, M.T., Tsay, H.J., Su, W.H., Chueh, F.Y., 1998. Changes in extracellular serotonin in rat hypothalamus affect thermoregulatory function. Am J Physiol. 274, R1260-7.

Lucki, I., Dalvi, A., Mayorga, A.J., 2001. Sensitivity to the effects of pharmacologically selective antidepressants in different strains of mice. Psychopharmacology (Berl). 155, 315-22.

Mashiko, D., Fujihara, Y., Satouh, Y., Miyata, H., Isotani, A., Ikawa, M., 2013. Generation of mutant mice by pronuclear injection of circular plasmid expressing Cas9 and single guided RNA. Sci Rep. 3, 3355.

Miyazaki, I., Asanuma, M., Murakami, S., Takeshima, M., Torigoe, N., Kitamura, Y., Miyoshi, K., 2013. Targeting 5-HT(1A) receptors in astrocytes to protect dopaminergic neurons in Parkinsonian models. Neurobiol Dis. 59, 244-56.

Naito, Y., Hino, K., Bono, H., Ui-Tei, K., 2015. CRISPRdirect: software for designing CRISPR/Cas guide RNA with reduced off-target sites. Bioinformatics. 31, 1120-3.

Nakamura, K., Sato, T., Ohashi, A., Tsurui, H., Hasegawa, H., 2008. Role of a serotonin precursor in development of gut microvilli. Am J Pathol. 172, 333-44.

Nathanson, J.L., Yanagawa, Y., Obata, K., Callaway, E.M., 2009. Preferential labeling of inhibitory and excitatory cortical neurons by endogenous tropism of adeno-associated virus and lentivirus vectors. Neuroscience. 161, 441-50.

Platt, R.J., Chen, S., Zhou, Y., Yim, M.J., Swiech, L., Kempton, H.R., Dahlman, J.E., Parnas, O., Eisenhaure, T.M., Jovanovic, M., Graham, D.B., Jhunjhunwala, S., Heidenreich, M., Xavier, R.J., Langer, R., Anderson, D.G., Hacohen, N., Regev, A., Feng, G., Sharp, P.A., Zhang, F., 2014. CRISPR-Cas9 knockin mice for genome editing and cancer modeling. Cell. 159, 440-55.

Rey, A.A., Purrio, M., Viveros, M.P., Lutz, B., 2012. Biphasic effects of cannabinoids in anxiety responses: $\mathrm{CB} 1$ and $\mathrm{GABA}(\mathrm{B})$ receptors in the balance of GABAergic and glutamatergic neurotransmission. Neuropsychopharmacology. 37, 2624-34.

Richardson-Jones, J.W., Craige, C.P., Guiard, B.P., Stephen, A., Metzger, K.L., Kung, H.F., Gardier, A.M., Dranovsky, A., David, D.J., Beck, S.G., Hen, R., Leonardo, E.D., 2010. 5-HT1A autoreceptor levels determine vulnerability to stress and response to antidepressants. Neuron. 65, 40-52.

Sentmanat, M.F., Peters, S.T., Florian, C.P., Connelly, J.P., Pruett-Miller, S.M., 2018. A Survey of Validation Strategies for CRISPR-Cas9 Editing. Sci Rep. 8, 888.

Shen, M.W., Arbab, M., Hsu, J.Y., Worstell, D., Culbertson, S.J., Krabbe, O., Cassa, C.A., Liu, D.R., Gifford, D.K., Sherwood, R.I., 2018. Predictable and precise template-free CRISPR editing of pathogenic variants. Nature.

Shikanai, H., Yoshida, T., Konno, K., Yamasaki, M., Izumi, T., Ohmura, Y., Watanabe, M., Yoshioka, M., 2012. Distinct neurochemical and functional properties of GAD67-containing 5-HT neurons in the rat dorsal raphe nucleus. J Neurosci. 32, 14415-26.

Singh, R., Kuscu, C., Quinlan, A., Qi, Y., Adli, M., 2015. Cas9-chromatin binding information enables more accurate CRISPR off-target prediction. Nucleic Acids Res. 43, e118.

Steinmetz, N.A., Buetfering, C., Lecoq, J., Lee, C.R., Peters, A.J., Jacobs, E.A.K., Coen, P., Ollerenshaw, D.R., Valley, M.T., de Vries, S.E.J., Garrett, M., Zhuang, J., Groblewski, P.A., Manavi, S., Miles, 
J., White, C., Lee, E., Griffin, F., Larkin, J.D., Roll, K., Cross, S., Nguyen, T.V., Larsen, R., Pendergraft, J., Daigle, T., Tasic, B., Thompson, C.L., Waters, J., Olsen, S., Margolis, D.J., Zeng, H., Hausser, M., Carandini, M., Harris, K.D., 2017. Aberrant Cortical Activity in Multiple GCaMP6-Expressing Transgenic Mouse Lines. eNeuro. 4.

Taniguchi, H., He, M., Wu, P., Kim, S., Paik, R., Sugino, K., Kvitsiani, D., Fu, Y., Lu, J., Lin, Y., Miyoshi, G., Shima, Y., Fishell, G., Nelson, S.B., Huang, Z.J., 2011. A resource of Cre driver lines for genetic targeting of GABAergic neurons in cerebral cortex. Neuron. 71, 995-1013.

Tsutsui-Kimura, I., Ohmura, Y., Yoshida, T., Yoshioka, M., 2017. Milnacipran affects mouse impulsive, aggressive, and depressive-like behaviors in a distinct dose-dependent manner. J Pharmacol Sci. 134, 181-189.

Turcotte-Cardin, V., Vahid-Ansari, F., Luckhart, C., Daigle, M., Geddes, S.D., Tanaka, K.F., Hen, R., James, J., Merali, Z., Beique, J.C., Albert, P.R., 2019. Loss of Adult 5-HT1A Autoreceptors Results in a Paradoxical Anxiogenic Response to Antidepressant Treatment. J Neurosci. 39, 1334-1346.

Veenema, A.H., Cremers, T.I., Jongsma, M.E., Steenbergen, P.J., de Boer, S.F., Koolhaas, J.M., 2005. Differences in the effects of 5-HT(1A) receptor agonists on forced swimming behavior and brain 5-HT metabolism between low and high aggressive mice. Psychopharmacology (Berl). 178, 151-60.

Whitaker-Azmitia, P.M., Murphy, R., Azmitia, E.C., 1990. Stimulation of astroglial 5-HT1A receptors releases the serotonergic growth factor, protein $\mathrm{S}-100$, and alters astroglial morphology. Brain Res. 528, 155-8.

Wood, M., Chaubey, M., Atkinson, P., Thomas, D.R., 2000. Antagonist activity of meta-chlorophenylpiperazine and partial agonist activity of 8-OH-DPAT at the 5-HT(7) receptor. Eur J Pharmacol. 396, 1-8.

Zhang, X.H., Tee, L.Y., Wang, X.G., Huang, Q.S., Yang, S.H., 2015. Off-target Effects in CRISPR/Cas9-mediated Genome Engineering. Mol Ther Nucleic Acids. 4, e264.

Zhuang, X., Masson, J., Gingrich, J.A., Rayport, S., Hen, R., 2005. Targeted gene expression in dopamine and serotonin neurons of the mouse brain. J Neurosci Methods. 143, 27-32. 
1 Table 1. Immunohistochemical analysis of GFP-positive cells

\begin{tabular}{cccc}
\hline \multirow{2}{*}{ TPH2 } & \multicolumn{3}{c}{$\begin{array}{c}\text { Number of labeled cells } \\
\text { (mean } \pm \text { S.E.M.) }\end{array}$} \\
\cline { 2 - 4 } & $\mathrm{GFP}^{+}$ & $\mathrm{TPH} 2^{+}$ & $\mathrm{GFP}^{+} / \mathrm{TPH}^{+}$ \\
\hline WT & $265.0 \pm 24.7$ & $172.0 \pm 3.5$ & $35.3 \pm 11.8$ \\
Cas9 & $309.3 \pm 23.5$ & $205.3 \pm 15.2$ & $33.3 \pm 6.2$ \\
\hline
\end{tabular}

\begin{tabular}{cccc}
\hline GAD67 & \multicolumn{3}{c}{$\begin{array}{c}\text { Number of labeled cells } \\
\text { (mean } \pm \text { S.E.M.) }\end{array}$} \\
\cline { 2 - 4 } & $\mathrm{GFP}^{+}$ & $\mathrm{GAD67}$ & $\mathrm{GFP}^{+} / \mathrm{GAD67}^{+}$ \\
\hline WT & $253.7 \pm 17.4$ & - & $204.7 \pm 15.3$ \\
Cas9 & $261 \pm 22.3$ & - & $220.3 \pm 32.9$ \\
\hline
\end{tabular}

\begin{tabular}{cccc}
\cline { 2 - 4 } & \multicolumn{3}{c}{$\begin{array}{c}\text { Percentages of co-labeled cells } \\
\text { (mean } \pm \text { S.E.M.) }\end{array}$} \\
\cline { 2 - 4 } & TPH2 $^{+}$ & GAD67 $^{+}$ & GFP $^{+}$ \\
in GFP & & in GFP & in TPH2 \\
\hline WT & $14.4 \pm 5.61$ & $80.6 \pm 0.53$ & $20.59 \pm 6.80$ \\
Cas9 & $10.61 \pm 1.4$ & $83.5 \pm 5.54$ & $15.97 \pm 2.08$ \\
\hline
\end{tabular}


3 Fig. 1. In vitro assessment of gRNAs by EGxxFP assay.

HEK293T cells were transfected with vector pAAV-U6-sgRNA-hSyn-Cre encoding gRNAs targeting the Htr1A locus plus vectors pX330 and pCAG-mHtr1A-EGxxFP (A-C), AAV:ITR-U6-sgRNA-hSyn-Cre alone (D-F), or pCAG-mHtr1a-EGxxFP alone (G). Forty-eight hours after transfection, EGFP fluorescence was recorded under fluorescence microscopy. Representative images obtained from two independent experiments are shown.

Fig. 2. Cre-dependent Cas9 expression and in vivo genome editing of Htr1a in the dorsal raphe nucleus by viral vector.

(A) Cre-dependent Cas9 knock-in mice (Cas9 mice) were microinjected with the viral vector into the dorsal raphe nucleus (DRN). Five weeks after injection, coronal sections containing the DRN were prepared and stained with anti-FLAG antibody. After staining, GFP (Green) and FLAG (Red) signals were observed by confocal microscopy. Bar $=100 \mu \mathrm{m}$. (B) The mismatch detection assay demonstrated insertion and deletion mutation (indel) formation in the DRN, but not in the cortex of viral vector-injected Cas9 mice. Frequency of indel formation (\%Indel) is expressed in mean \pm SEM. $n=7$. The uncleaved band was $640 \mathrm{bp}$. The cleaved bands were $370 \mathrm{bp}$ and $270 \mathrm{bp}$. (C) The mismatch detection assay of the top four candidates for off-target site cleavage showed no detectable indel formation. (D) Sanger sequencing chromatograms of the PCR products containing the target site obtained from the DRN of viral vector-injected Cas9 mice and wild type (WT) littermates showed indel formation only in the Cas9 mice (Cas9). Arrow indicates the predicted cut site. (E) TIDE analysis showed mostly frameshift mutations in Htr1a of viral vector-injected Cas9 mouse DRN. $n=5$. The bars represent the mean, and the lines represent the SEM.

\section{Fig. 3. Histological characterization of Cas9 expressing cells in the dorsal raphe nucleus.}

Cre-dependent Cas9 knock-in mice (Cas9; lower panels) and wild type littermates (WT; upper panels) were microinjected with viral vector into the dorsal raphe nucleus (DRN). Five weeks after microinjection, coronal sections containing the DRN were prepared and stained with anti-TPH2 (left panels) or anti-GAD67 (right panels) antibody. After staining, GFP and TPH2/GAD67 signals were observed by confocal microscopy. Bar $=100 \mu \mathrm{m}$.

Fig. 4. Effect of in vivo CRISPR/Cas9-mediated Htr1a gene knockout in DRN neurons on 5-HT $1 \mathrm{~A}$ agonist-induced hypothermia.

(A) Five weeks after microinjection of viral vector into the DRN, hypothermia induced by intraperitoneal (i.p.) administration of 8-OH-DPAT, a 5- $\mathrm{HT}_{1 \mathrm{~A}}$ agonist, was attenuated in Cre-dependent Cas9 knock-in mice (Cas9: n=7) compared to wild type littermates (WT: $n=6)$. (B) Hypothermia induced by i.p. administration of NLX-112, a selective 5- $\mathrm{HT}_{1 \mathrm{~A}}$ agonist, was also attenuated in Cas9 $(n=10)$ compared to WT $(n=8)$. (C) Immobility time in the forced swim test was reduced in Cas9 $(n=10)$ compared to WT $(n=8)$ after i.p. injection of fluoxetine, a selective serotonin reuptake inhibitor. ${ }^{*} P<0.05,{ }^{* *} P<0.01$. 
2 Fig. 5. The effects of 5-HT $1 \mathrm{~A}$ receptor agonist on 5-HT metabolism in 3 CRISPR/Cas9-mediated 5-HT 1 A receptor knockout mice and wildtype mice.

4 (A-D) Thirty minutes after administration of NLX-112, the brain tissue (DRN: dorsal raphe 5 nucleus, MRN: median raphe nucleus, DS: dorsal striatum, VH: ventral hippocampus) and urine 6 contents of 5-HT and 5-HIAA were measured. The 5-HIAA/5-HT ratio was calculated as a measure 7 of 5-HT turnover. (A, B) In the brain (A) or urine (B), 5-HT, 5-HIAA and 5-HIAA/5-HT were not 8 changed by the administration of NLX-112 in normal C57BL/6N mice (saline: $\mathrm{n}=4$, NLX-112: $9 \mathrm{n}=4)$, except for 5-HIAA/5-HT in the DRN. (C, D) In the brain (C) or urine (D) 5-HT, 5-HIAA or 10 5-HIAA/5-HT did not differ between Cas9 transgenic $(n=9)$ and WT controls $(n=8) .{ }^{*} P<0.05$ 
2 Supplementary Fig. S1. A representative image of virally infected area.

3 Cre-dependent Cas9 knock-in mice were microinjected with the viral vector containing sgRNA for

$4 \quad H t r 1 a$ (sgHtr1a) into the dorsal raphe nucleus. Five weeks after microinjection, GFP fluorescence 5 was observed by fluorescence microscopy. (A) The representative image of the maximal spread of the GFP-positive cells. (B) The representative image of the minimum spread of the GFP-positive cells. (C) The diagram of the spread of the GFP-positive cells. Black dotted line and gray dotted line indicate the boundary of the maximum and the minimum spread of GFP fluorescence, respectively. aq= cerebral aqueduct.

\section{Supplementary Fig. S2. Sanger sequencing chromatograms of the PCR products containing} target site.

The viral vector containing sgRNA for Htr1a (sgHtr1a) or lacking sgRNA (sgRNA(backbone)) was microinjected into the dorsal raphe nucleus (DRN) of Cre-dependent Cas9 knock-in mice (Cas9) and wild type littermates (WT). Five weeks after injection, PCR products were obtained from the dorsal raphe nucleus and sequenced. Arrow indicates the predicted cut site.

Supplementary Fig. S3. 5-HT $1 \mathrm{~A}$ agonist-induced hypothermia in Cre-dependent Cas9 knock-in mice injected with viral vector lacking sgRNA and the effect of fluoxetine on wildtype naïve mice in the forced swim test.

(A) Cre-dependent Cas9 knock-in mice were microinjected with a viral vector lacking sgRNA Htr1a (WT: n=6). 8-OH-DPAT-induced hypothermia level was comparable between groups. (B) Wild type mice were injected with saline $(n=6)$ or fluoxetine $(10 \mathrm{mg} / \mathrm{kg}: \mathrm{n}=5)$. Thirty minutes after injection, the forced swim test was performed. Immobility time was comparable between groups. 
gRNA \#1, pX330 gRNA \#2, pX330 mHtr1A-EGxxFP mHtr1A-EGxxFP

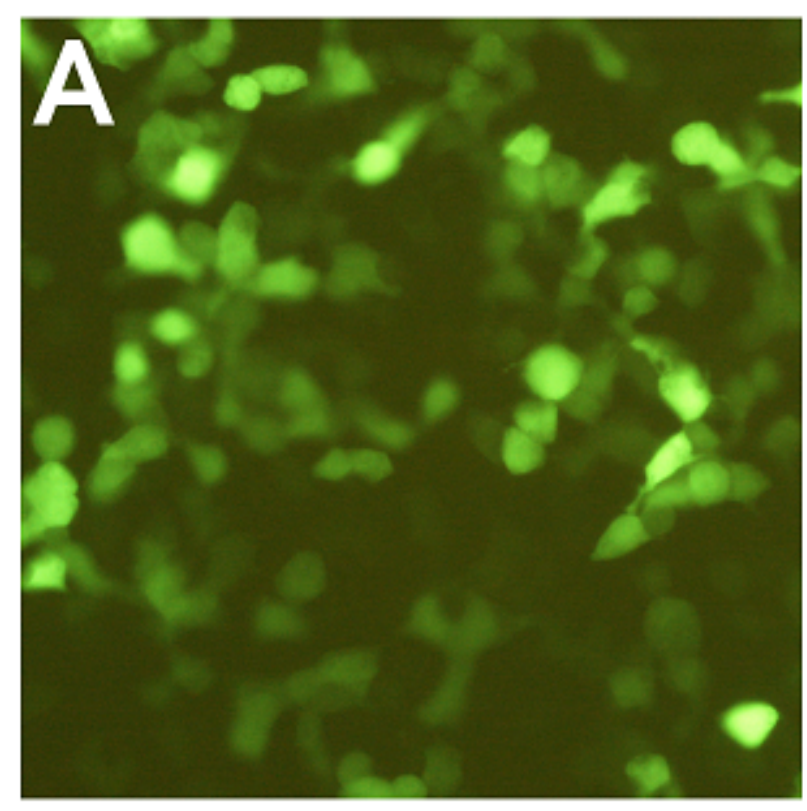

gRNA \#1 only

\section{D}

mHtr1A-EGxxFP only

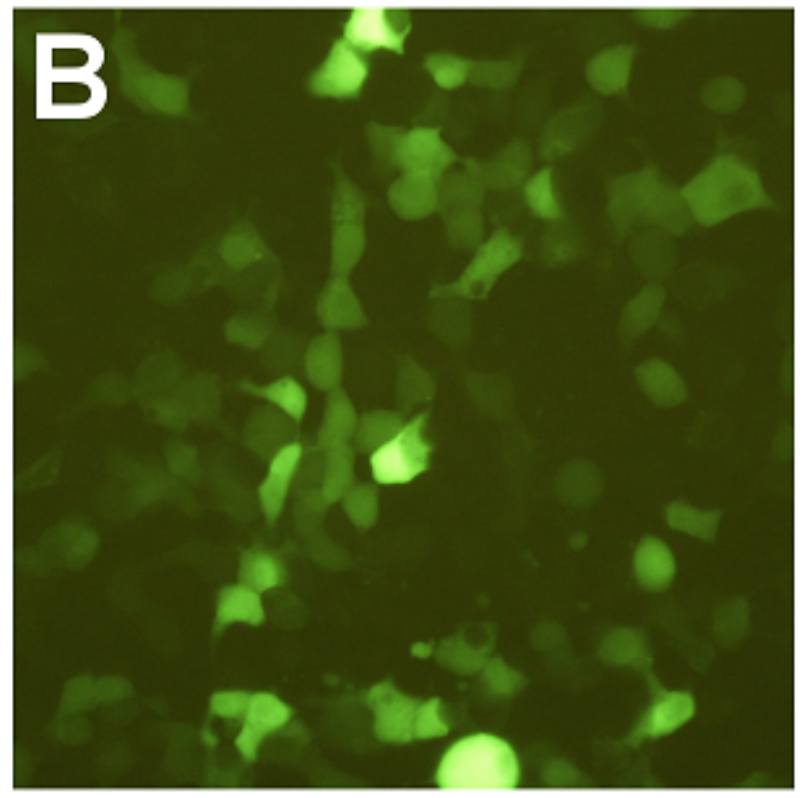

gRNA \#2 only

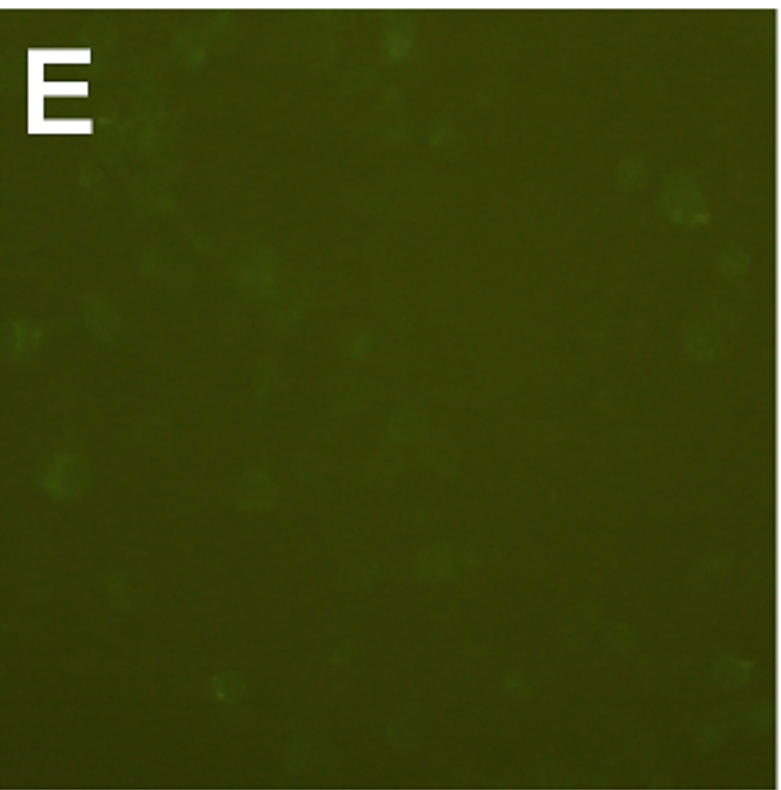

gRNA \#3, pX330 mHtr1A-EGxxFP

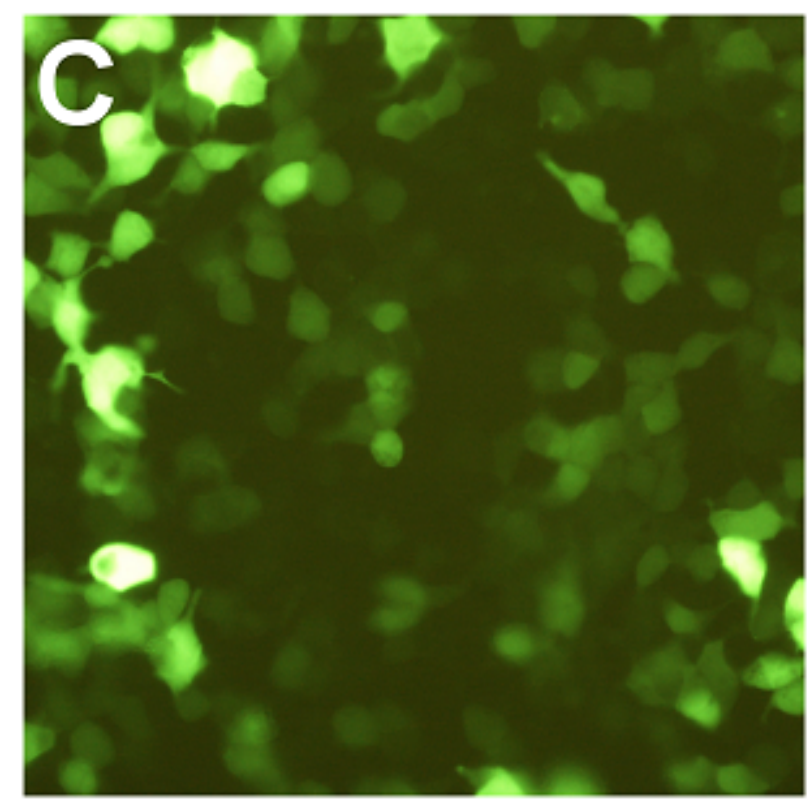

gRNA \#3 only

$\mathbf{F}$ 
A

Merge

GFP

FLAG
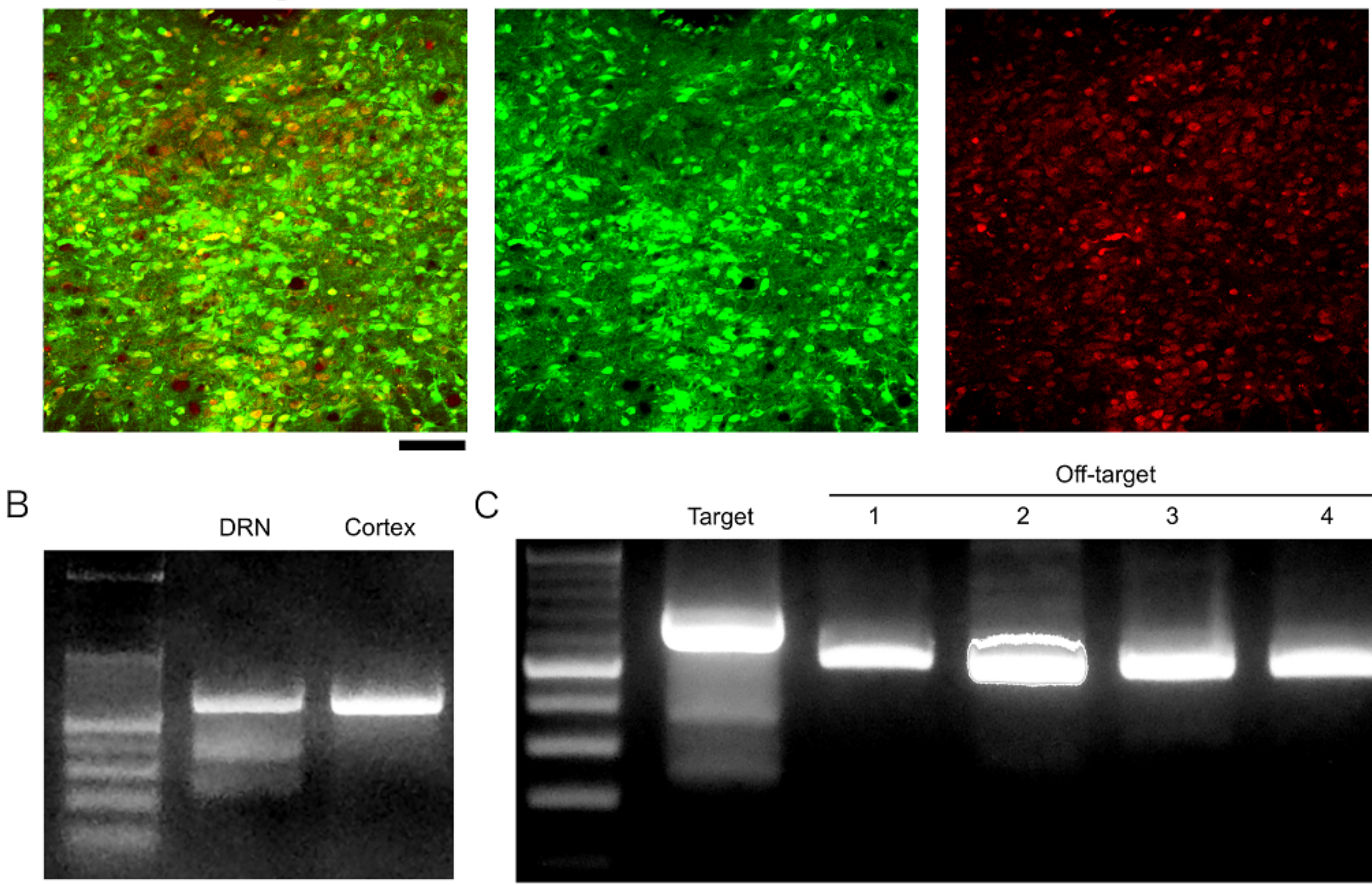

C

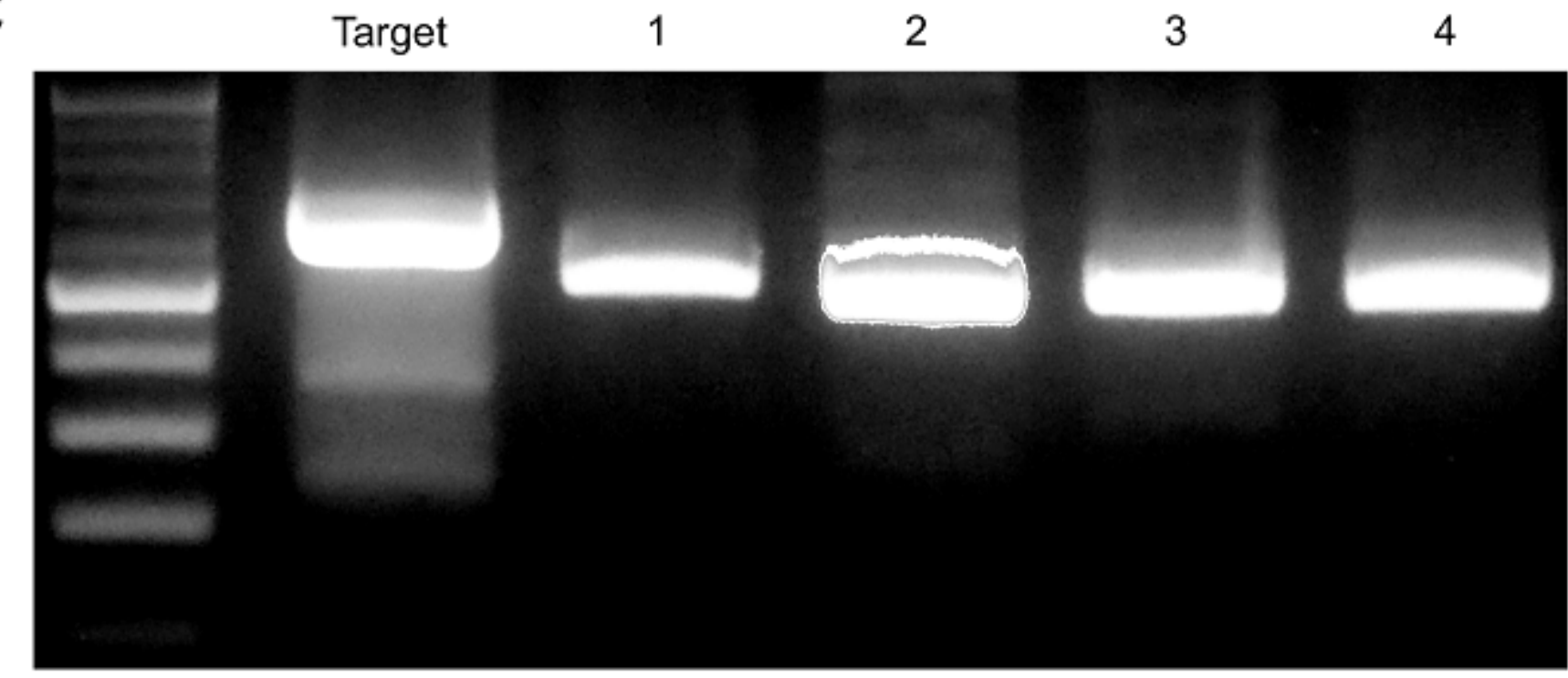

\%Indel $=8.65 \pm 1.67$

D

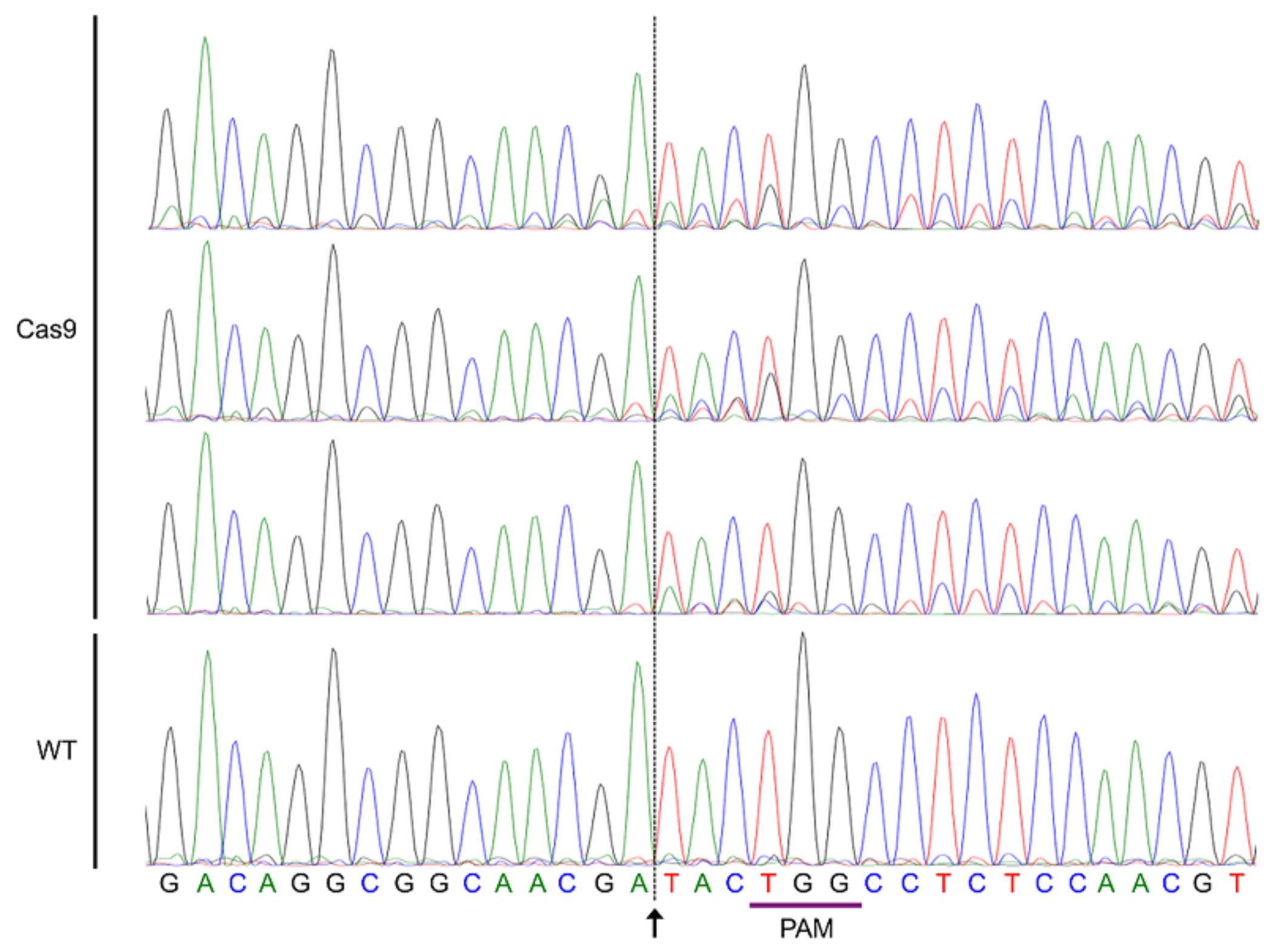

E

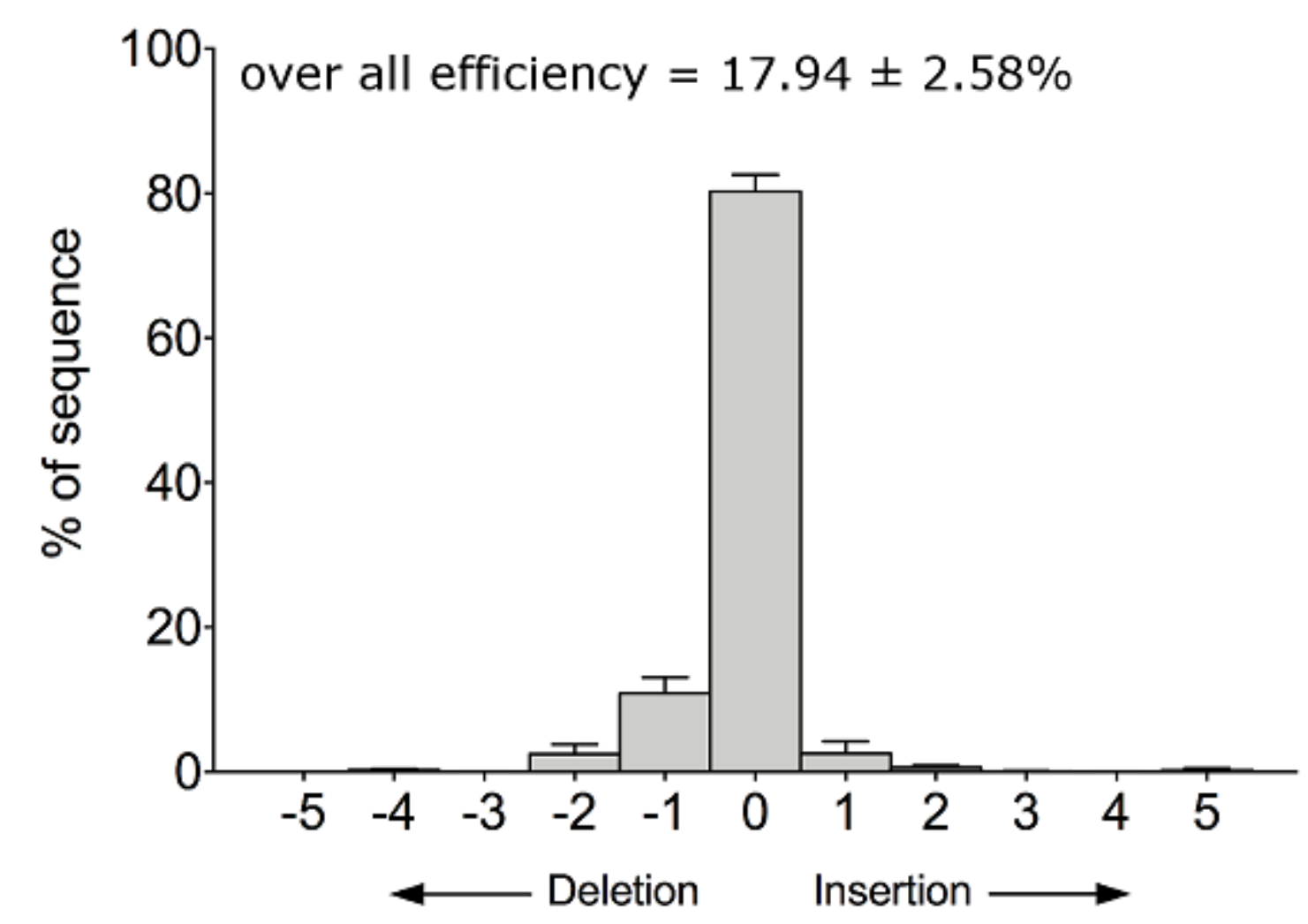




\section{GFP / TPH2}

\section{GFP / GAD67}
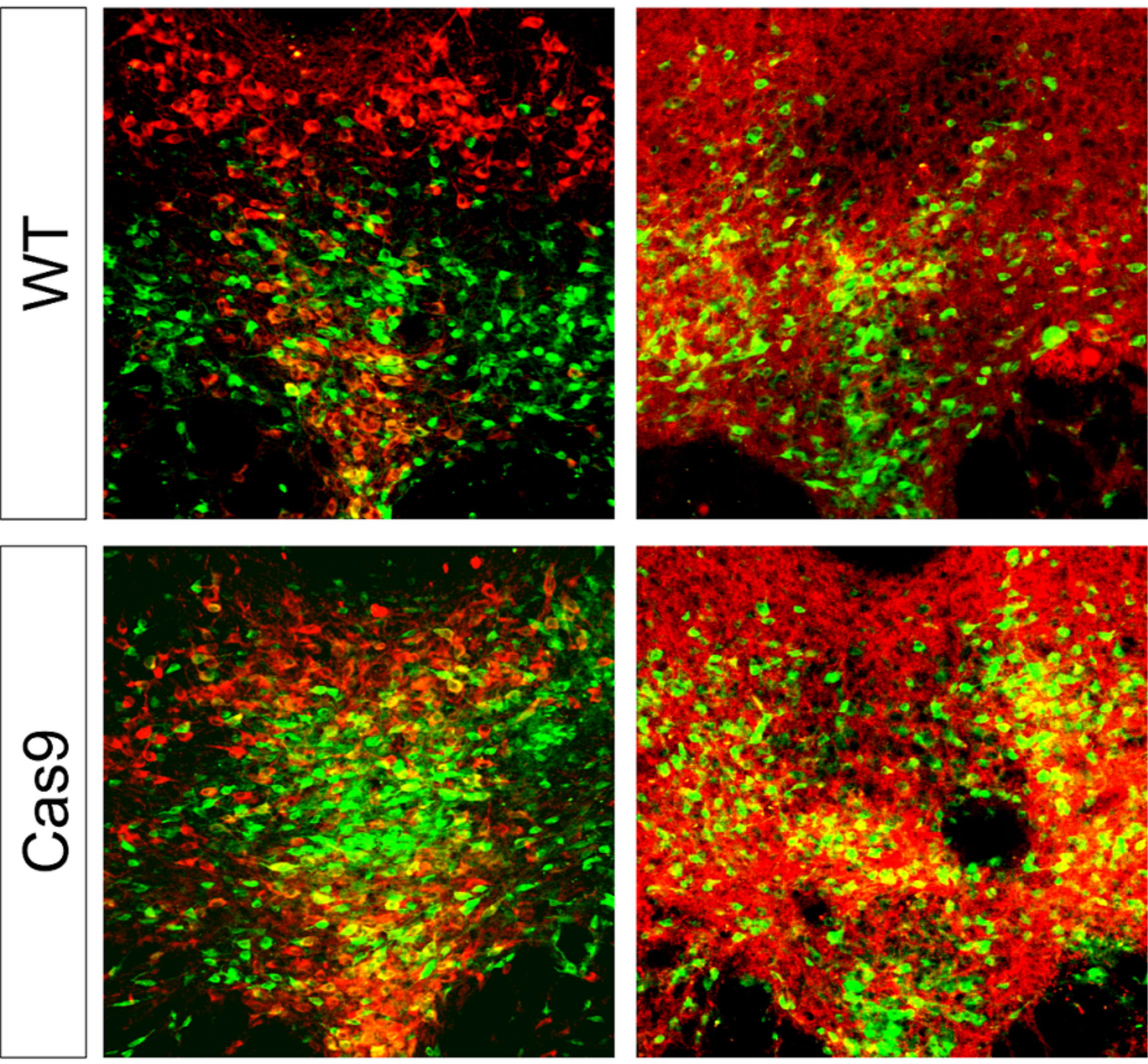


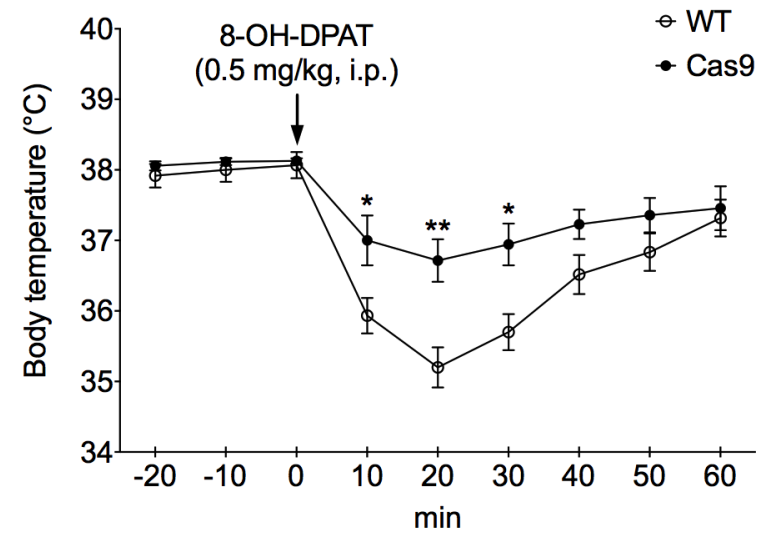

C

B
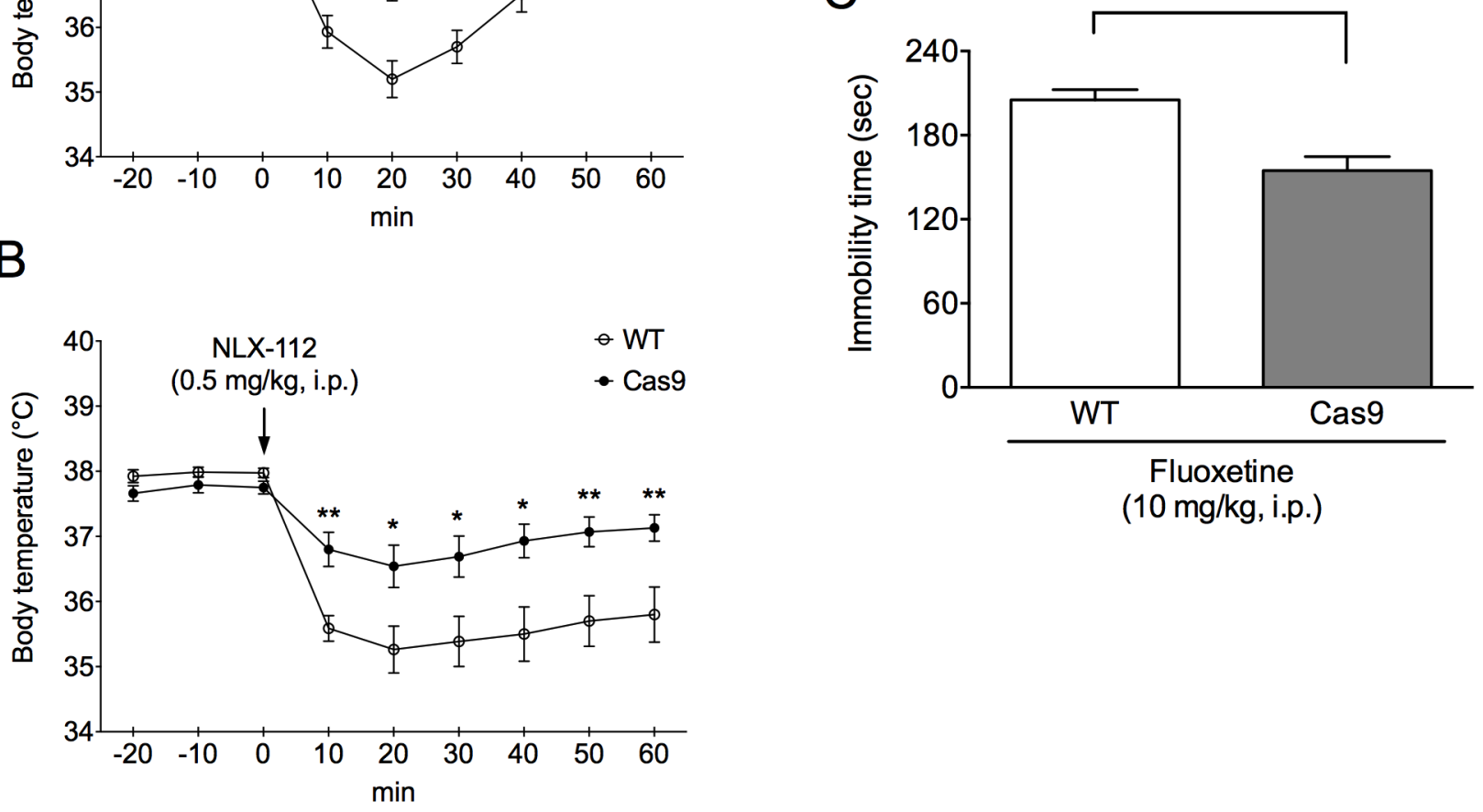

Fluoxetine

(10 mg/kg, i.p.) 


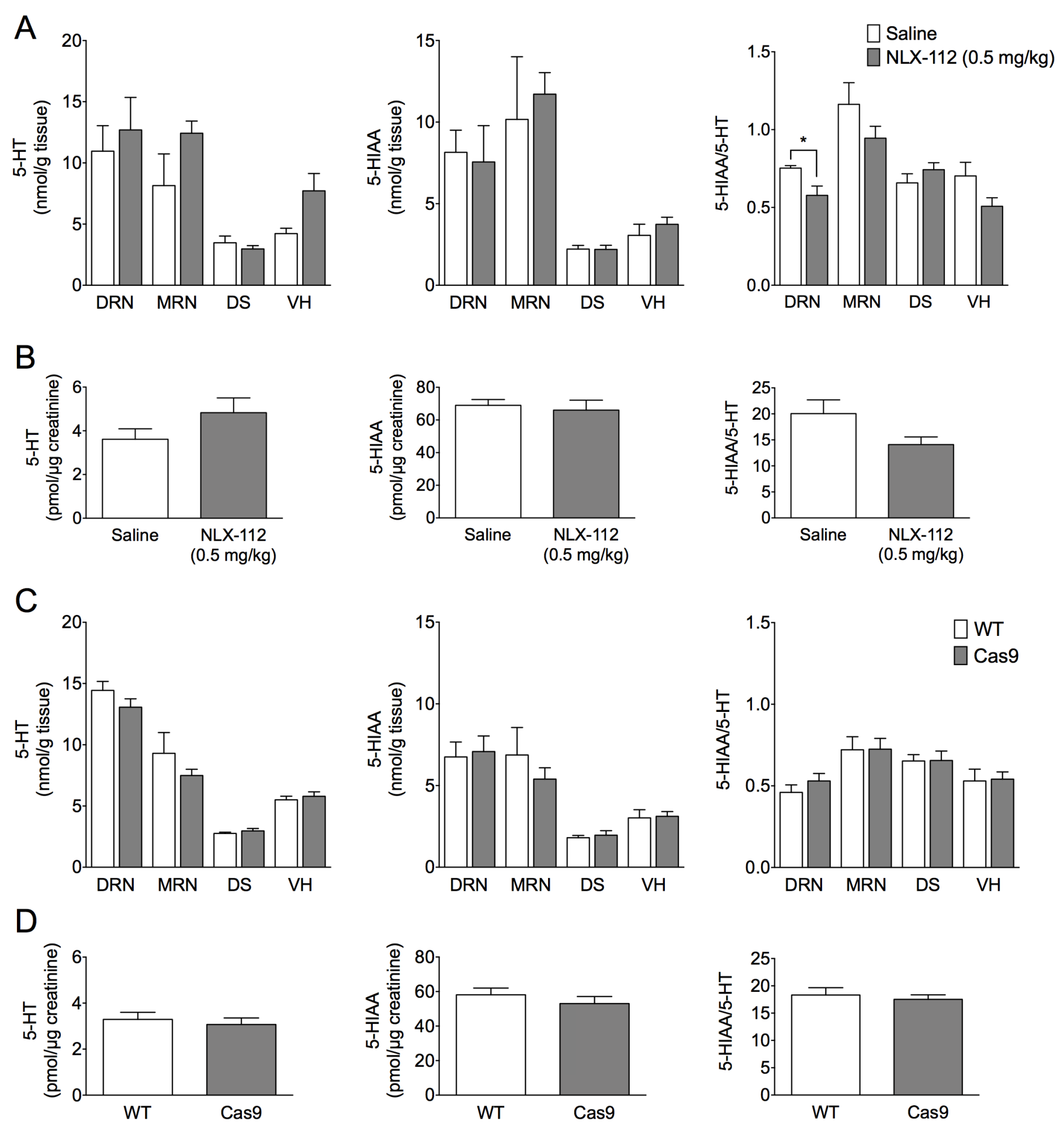

